\title{
Una propuesta de valoración de patrimonio urbano a la luz de Panoramio, una fuente Big-Data. El caso del centro de Bogotá
}

\author{
An Urban Heritage Assessment with Panoramio,
} a Big-Data source. A Study of Downtown Bogotá

Uma proposta de valorização do patrimônio urbano à luz do Panoramio, uma fonte de Big-Data. O caso do centro de Bogotá

Amparo De Urbina González*

Recibido: 20 de noviembre de 2020

Aprobado: 25 de marzo de 2021

https://doi.org/10.12804/revistas.urosario.edu.co/territorios/a.9927

Para citar este artículo

De Urbina González, A. (2021). Una propuesta de valoración de Panoramio, una fuente Big-Dara. El caso del centro de Bogotá. Territorios (45), pp. 87-107. https://doi.org/10.12804/revistas.urosario. edu.co/territorios/a.9927

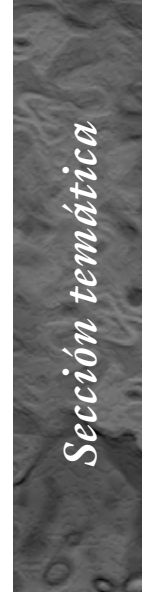

* Docente investigadora vinculada al Centro de Investigaciones sobre Dinámica Social, Universidad Externado de Colombia, Facultad de Ciencias Sociales y $\mathrm{Hu}$ manas, Área de estudio, Humanidades Digitales. Correo electrónico: amparo.deurbina@uexternado.edu.co. ORCID: bttps://orcid.org/00000002-4939-8297 
Palabras clave

Humanidades digitales; paisaje urbano; patrimonio urbano; centro de Bogotá; Panoramio.

Keywords Digital humanities; urban landscape; urban heritage; downtown Bogotá; Panoramio.

Palavras-chave Humanidades digitais; paisagem urbana; patrimônio urbano; centro de Bogotá;

Panoramio.

territarias 45

\section{RESUMEN}

La propuesta se enmarca en el proyecto de Amparo De Urbina que se desarrolla en el doctorado en Estudios Sociales, de la Universidad Externado, Facultad de Ciencias Sociales y Humanas, que tiene como objetivo identificar y caracterizar escenarios urbanos relevantes del centro de Bogotá, mediatizadas por la percepción colectiva de población local y foránea, desde una perspectiva relacional como insumo para complementar la valoración patrimonial vigente. Se busca hacer una lectura del patrimonio urbano, a la luz de imágenes del centro que algunos visitantes reportaron diariamente a Panoramio entre 2007 y 2014, una plataforma que hasta 2016 exhibía las fotografías de los lugares que los mismos usuarios registraban y georreferenciaban con base en sus experiencias en el lugar. Los resultados que se presentan en este artículo abordan tipologías de encuadre, ubicación del fotógrafo y la evidencia de algunos eventos propios del centro de la ciudad.

\section{ABSTRACT}

The proposal is part of the project of Amparo De Urbina in the doctorate in Social Studies, from the Externado University-Faculty of Social and Human Sciences. Its objective is to identify and characterize relevant urban settings in the center of Bogotá. Scenarios mediated by the collective perception of the local and foreign population from a relational perspective. This as an input to complement the current asset valuation. It seeks to make a reading of urban heritage, in the light of images of the center that some visitors reported daily to Panoramio between 2007 and 2014. Panoramio was a platform that until 2016 exhibited photographs of the places that the same users registered and georeferenced based on to their experiences in the territory. The results presented in this article show types of framing, location of the photographer and the evidence of some events typical of the city center.

\section{RESUMO}

A proposta faz parte do projeto de doutorado de Amparo De Urbina que se desenvolve em Estudos Sociais, na Universidade Externado-Faculdade de Ciências Sociais e Humanas, que visa identificar e caracterizar configurações urbanas relevantes no centro de Bogotá, mediada pela percepção coletiva da população local e estrangeira, a partir de uma perspectiva relacional como um insumo para complementar a avaliação patrimonial vigente. Pretende-se fazer uma leitura do patrimônio urbano, à luz das imagens do centro, que alguns visitantes reportaram diariamente ao Panoramio entre 2007 e 2014, plataforma esta que até 2016 exibia as fotografias dos locais que os mesmos usuários registravam e georreferenciavam com base nas suas experiências no local. Os resultados apresentados neste artigo abordam tipologias de enquadramento, a localização do fotógrafo e a evidência de alguns eventos típicos do centro da cidade. 


\section{Introducción}

Esta propuesta se enmarca en el proyecto de investigación de Amparo De Urbina que se desarrolla en el doctorado en Estudios Sociales, de la Universidad Externado, Facultad de Ciencias Sociales y Humanas, cuyo objetivo es identificar y caracterizar escenarios urbanos relevantes del centro de Bogotá, mediatizados por la percepción colectiva de población local y foránea, desde una perspectiva relacional como insumo para complementar la valoración patrimonial vigente. Se busca hacer una lectura del patrimonio urbano, a la luz de imágenes del centro que algunos visitantes reportaron diariamente entre 2007 y 2014 a Panoramio, una plataforma que hasta $2016^{1}$ exhibía las fotografías de los lugares que los mismos usuarios registraban y georreferenciaban con base en sus experiencias en el lugar; la temporalidad está establecida por la disponibilidad de la fuente.

El acceso a un poco más de 6000 imágenes capturadas y compartidas por alrededor de 1080 usuarios de Panoramio que visitaron el centro de Bogotá se traduce en una alternativa muy interesante para responder a una pregunta que se hizo desde el urbanismo y las ciencias cognitivas desde mediados del siglo 20 y que está vigente relacionada con cómo aproximarse a la ciudad, a la luz del paisaje urbano que, desde su nacimiento en el urbanismo y su evolución en el marco de la geografía humanista, deja elementos que permiten ser retomados para la aproximación al centro de Bogotá, a través de las fotos compartidas por los usuarios, asumiendo una escala micro, la de los escenarios urbanos de Gordon Cullen y Kevin Lynch.

La respuesta, a partir de un ejercicio como el que se está desarrollando, no hubiera sido posible hace 10 o 15 años pues no se podía acceder a una muestra tan grande de imágenes en tan poco tiempo. La fuente elegida para el ejercicio es Panoramio, una red social que pertenece a la Web 2.0, lo que implica que permite a los usuarios que participan en la misma compartir imágenes con el potencial de mostrar los atractivos de un lugar (Gutiérrez-Puebla et al., 2016). Esta plataforma pionera en georreferenciar fotos tomadas por usuarios, se consultaba a través de Google Earth hasta 2016 ( $\mathrm{Fi}^{-}$ gura 2), donde se exhibían las fotografías (Pardo, 2015).

Las fotos que toman los visitantes del centro y suben a las redes sociales son manifestaciones contemporáneas que se relacionan con la necesidad de compartir una experiencia. Mostrar en redes sociales las experiencias del visitante, a través de imágenes permite que el observador se proyecte en una vivencia futura o que recree vivencias anteriores, evidenciando valores contemporáneos sociales, culturales, políticos y económicos, construyendo estilos de vida y de consumo. La relación entre turismo y fotografía no es un hecho contemporáneo, emerge en el
${ }^{1}$ La plataforma permitió a los usuarios subir sus fotos hasta 2014 y las mismas fueron exhibidas hasta 2016, cuando fue cerrada permanentemente. Actualmente, el acceso a redes sociales que comparten fotos es bastante más amplio, por lo que pueden considerarse nuevas alternativas (previa evaluación de posibilidad de descarga de datos y politicas de la fuente) como Flikr, Instagram, o la red que dio continuidad a Panoramio, que es Local Guides de Google.

territarias 45 89 
mismo contexto histórico de la modernidad y se desarrolla en sintonía con el deseo de viajar y captar las sensaciones visualizadas durante el desplazamiento en el recorrido (Menezes \& Gândara, 2015). Las imágenes se consideran una forma de expresión subjetiva, una manifestación cultural - actualmente de uso popularque forma parte de la cotidianidad; es un agente social el que produce la foto y la emite a través de redes sociales, lo que no es una acción imparcial, es más bien una forma de mostrarle al mundo su propia mirada. Una foto es producto de un ejercicio donde se opta, demarca, sugiere e incluso impone una visión del mundo (Suárez, 2008, p. 24).

La investigación se enmarca en el campo de las humanidades digitales, pues reconoce el impacto de las redes sociales en la vida cotidiana de los usuarios y el potencial de los rastros de esta relación en investigaciones enmarcadas en las humanidades. En este caso concreto, se trabajó con un pequeño volumen de la información disponible de Panoramio - alrededor de 6000 imágenes captadas por alrededor de 1080 usuarios en el centro de Bogotá entre 2007 y 2014-, que fue la base a partir de la cual se construyeron una serie de atributos adicionales derivados de la imagen, del usuario y de la localización espacial de la imagen, logrando profundizar en categorías, que desde la fuente en bruto no hubiera sido posible (Meneses Rocha, 2018).
Se acude a la Teoría de Actor Red (TAR) como soporte teórico, cuyo aporte a los estudios urbanos es el de concebir sus objetos de estudio - en este caso la ciudad-como resultado de las diversas posibilidades de relaciones entre los actores vinculados a ella - humanos y no humanos-; este abordaje teórico constituye una alternativa pertinente para dar cuenta de fenómenos urbanos contemporáneos, difíciles de acotar por su permanente y rápida transformación. El resultado de abordar un objeto de estudio en clave de la TAR, es el de generar descripciones y explicaciones detalladas de los actores identificados en el ensamblaje, en función de sus relaciones por encima de sus atributos (Ponce Solórzano, 2014).

El resultado del abordaje implica reconocer que, la lectura que se va a hacer del centro de Bogotá a la luz del paisaje, es producto de las relaciones entre el territorio de estudio, legitimado como patrimonio a través de los discursos institucionales que lo legitiman como tal, el visitante, las imágenes que registra con su cámara, Panoramio - la plataforma que aloja las imágenes compartidas por cada usuario-, y la Web 2.0 como plataforma que permite la construcción colectiva de la información a la que pertenece Panoramio; todo esto entre 2007 y 2014. Las relaciones entre todos estos elementos heterogéneos - considerados desde la TAR como actores-, condicionan el abordaje propuesto del centro de Bogotá. 
El objetivo de este artículo es el de mostrar los primeros hallazgos del ejercicio descrito. El documento se desarrolla en cinco partes; en la primera titulada Fotos y paisaje urbano, se establece la definición de paisaje adoptada en la investigación y se justifica la utilidad de las fotos como herramienta para este abordaje de paisaje urbano en busca de escenarios relevantes; en la segunda parte titulada Panoramio, la fuente de información, se describe la plataforma y su funcionamiento con el fin de justificar su pertinencia; en la tercera parte titulada La base de datos se describe cómo se descargó la base de datos de Panoramio y su descripción general; en la cuarta parte se busca mostrar los Primeros hallazgos desde tres dimensiones, una estética que se refiere a las tipologías de encuadre, una espacial, que se refiere a la ubicación en el territorio de los fotógrafos y finalmente una dimensión temporal, que evidencia eventos importantes en el área de estudio; la última parte del texto se refiere a las reflexiones finales.

\section{Fotos y paisaje urbano}

Recientemente, en el contexto internacional existe un referente obligado - aunque no suficientemente desarrollado- para la aproximación a centros históricos. Entrando al siglo XXI, en el Memorando de Viena (2005), y tras seis años de debates y reuniones de expertos, la $36^{\mathrm{a}}$ Conferencia General de UNESCO adoptó en 2011 una Recomendación, que propone una nueva aproximación al patrimonio urbano denominado Paisaje Urbano Histórico, cuyo concepto central es el paisaje; esto supone la adaptación de la valoración y gestión del patrimonio urbano a los requerimientos que plantea la sostenibilidad, además de una consideración de las relaciones entre los diversos tipos de patrimonio (Lalana, 2011, p. 16). El avance supone también ir más allá de la conservación física, para reconocer la dimensión social del patrimonio urbano, buscando dar sostenibilidad en el tiempo a los valores propios de los centros históricos.

Sin embargo, acudir al paisaje para aproximarse a la ciudad desde la percepción, no es algo nuevo, se abordó hace casi 60 años, desde el urbanismo; la escuela de paisaje que surge de la planificación urbana condiciona el paisaje urbano con la idea de proyecto. Su concepción responde a lograr una aproximación analítica a la ciudad, a partir de la percepción, con la intención de generar recomendaciones para la intervención de escenarios urbanos, de manera que los usuarios logren generar interpretaciones emotivas y significados singulares del espacio urbano. En este contexto Gordon Cullen desarrolla una aproximación más formal a la percepción de la ciudad, y Kevin Lynch plantea la percepción del observador en relación a la orientación espacial (Cruz Pérez \& Español Echániz, 2009, pp. 21-23).

A partir de Lynch y Cullen se derivan una variedad de lecturas del paisaje urbano donde se pueden resaltar los aportes de territarios 45

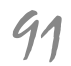


${ }^{2}$ Se inició en la psicología con Tolman (1932, 1948), quien en sus trabajos sobre "Mapas Cognitivos en ratas y los Hombres" ha acuñado el término de mapa cognitivo (Portugali, 2011, p. 117).

${ }^{3}$ Más tarde se ha originado una vez más, independientemente de Tolman, en la arquitectura y el urbanismo con Lynch (1960) La imagen de la ciudad (Portugali, 2011, pp. 117-118).

${ }^{4}$ Si bien es difícil señalar un solo titular en la geografía, el papel de David Lowenthal de 1961 fue esencial, aunque su enfoque específico no se siguió (Portugali, 2011, p. 118).

\section{territarias 45}

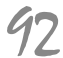

Allan Jacobs, que retoma el análisis escénico de Lynch para leer vías urbanas como espacios públicos; Christine Boyer, que acude al recurso de la monumentalidad de los edificios singulares; y Anne Whiston y Spirn, quienes amplían la teoría del lugar construyendo toda una hermenéutica del paisaje (Cruz Pérez \& Español Echániz, 2009, pp. 21-23). Si bien La imagen de la ciudad (Lynch, 1998) y Paisaje urbano (Cullen, 1974) se convirtieron en referentes sobre paisaje urbano con aplicación a la ciudad occidental contemporánea, que entusiasmaron especialmente a arquitectos y urbanistas a abordar aspectos perceptivos de los paisajes urbanos, ninguna de las obras tiene desarrollos teóricos suficientes (Zoido Naranjo, 2012, p. 34).

La pregunta por la percepción de la ciudad se da también en un contexto paralelo - en el que se enmarca la experiencia de Kevin Lynch-, en un momento en el que el estudio de la cognición se vincula con el estudio de las ciudades, relacionando tres disciplinas: la psicología, ${ }^{2}$ la arquitectura $^{3}$ y la geografía humana. ${ }^{4}$ Desde la psicología - campo en el que se acuña el término de mapa cognitivo gracias a los aportes de Tolman- estaban interesados en los procesos dentro de la mente; desde la arquitectura en las formas en que la estructura arquitectónica de edificios y ciudades son imaginadas, esto con el fin de diseñar mejores ciudades; y la geografía estaba buscando un modelo de comportamiento para mejorar la teoría de la localización (Portugali, 2011).
La pregunta en torno a la percepción de la ciudad - el paisaje urbano-desde la geografía humana se retomó luego de la etapa de cambio de paradigma en la que entró, entre las décadas de los 60 y 70 ; de esa transición emerge una geografía humana que se inclina hacia el estudio de las sociedades. En esta visión renovada el espacio geográfico, la ciudad se concibe como un espacio poblado por personas que establecen lazos entre sí y cuando estas relaciones son duraderas se establecen vínculos que son realidades sociales y materiales que organizan el espacio. Reconocerse en el paisaje, es el resultado de una relación sensorial que trasciende el vínculo familiar, aspecto que fue muy bien tratado en la obra de $\mathrm{Yi} \mathrm{Fu}$ Tuan (1974 y 1976) (Vargas Ulate, 2012).

El paisaje urbano es por lo tanto asumido en el marco de esta investigación desde una escala micro, que se traduce a una perspectiva peatonal pertinente para identificar escenarios urbanos. Las fotos compartidas de esta pieza urbana de la ciudad se consideran un material pertinente para identificar y caracterizar escenarios relevantes del paisaje urbano en el centro de Bogotá. Las fotos que toman los usuarios y suben a las redes sociales son manifestaciones contemporáneas que se relacionan con la necesidad de compartir una experiencia. Mostrar en redes sociales las experiencias del visitante, a través de imágenes permiten que el observador se proyecte en una vivencia turística futura o evoque vivencias pasadas, evidenciando 
valores contemporáneos sociales, culturales, políticos y económicos, construyendo estilos de vida y de consumo. La relación entre visitante y fotografía no es un hecho contemporáneo, emerge en el mismo contexto histórico de la modernidad, y se desarrolla en sintonía con el deseo de viajar y captar las sensaciones visualizadas durante el desplazamiento en el recorrido (Menezes \& Gândara, 2015).

Las imágenes se consideran una forma de expresión subjetiva, una manifestación cultural - actualmente de uso popular-, que forma parte de la cotidianidad; es un agente social el que produce la foto y la emite a través de redes sociales, lo que no es una acción imparcial, es más bien una forma de mostrarle al mundo su propia mirada. Una foto es producto de un ejercicio donde se opta, demarca, sugiere e, incluso, impone una visión del mundo (Suárez, 2008, p. 24). Permite esbozar las relaciones que los visitantes construyen con el territorio y hacer una lectura transversal: qué es lo más fotografiado, cuáles son los encuadres más recurrentes, en qué época del año, en qué momento del día, tal vez los recorridos que pudieron hacer, por ejemplo (Banks, 2010).

\section{Panoramio, la fuente de información}

El comportamiento espacial de algunos turistas y visitantes puede ser rastreado a través de redes sociales asociadas a fuentes de datos, que registran la huella digital de sus actividades, como Panoramio; esta plataforma pionera en la Web 2.0 o web social tenía como objetivo ilustrar el mundo con fotos geoposicionadas, compartidas por la comunidad con base en sus experiencias en el territorio (figura 1$){ }^{5}$ Fue fundada en julio de 2005 por los españoles Joaquín Cuenca y Eduardo Manchón, lanzada en octubre del mismo año, vendida a Google en mayo de 2007 y cerrada 2014 (Jiménez Cano, 2014).

Una vez lanzada creció rápidamente, alcanzando 50 mil fotos compartidas, lo que llamó la atención inmediata de diversos medios en Estados Unidos (AlicanTEC, s. f.); pocos meses después, y debido a que fue una de las primeras aplicaciones desarrolladas para Google Earth, Google busco contacto con sus creadores; el interés de esta gran empresa en la aplicación se evidenció cuando incorporaron directamente las fotos dentro

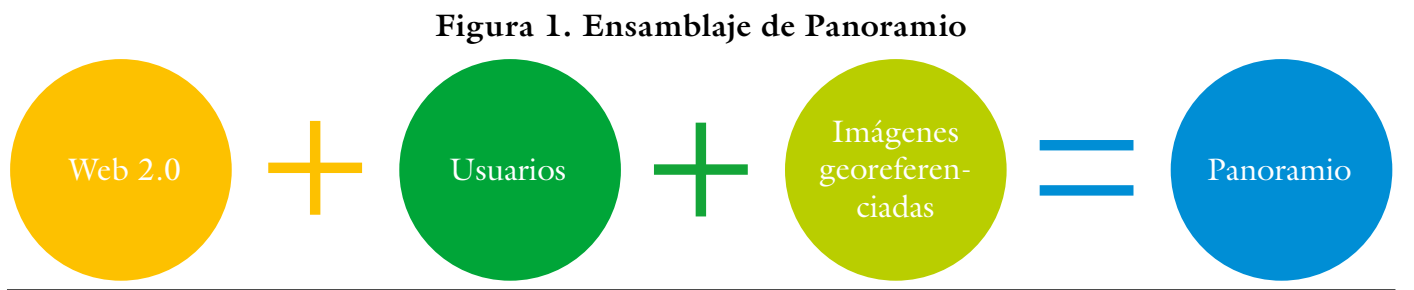

Fuente: elaboración propia.

UNA PROPUESTA DE VALORACIÓN DE PATRIMONIO URBANO A LA LUZ DE PANORAMIO
${ }^{5}$ Información que puede consultarse en https:// labs.mapbox.com/ labs/twitter-gnip/locals/\#3/23.16/-38.14

territarios 45 93 
${ }^{6}$ https://www.change. org/p/google-larry-andsergey-google-keep-thepanoramio-communityalive

7 https://groups.google. com/forum/\#!forum/ panoramio-spanish territarias 45 94 de su "mapamundi interactivo" (figura 2), multiplicando por 30 el tráfico en un solo día (Fernández, 2008).

En 2006 Google hizo un primer intento de compra de Panoramio a sus creadores, quienes rechazaron la propuesta por la baja oferta económica; el segundo intento de compra se concretó en 2007. En 2014 Google anuncia el cierre de Panoramio, detonando una fuerte reacción por parte de la comunidad fiel a la aplicación y encargada de alimentar permanentemente el servicio con imágenes actualizadas de excelente calidad (Jiménez Cano, 2014). Luego de una petición de Change.org que reunió 10.514 firmas $^{6}$ pidiendo que no cerraran Panoramio, la empresa desistió del cierre definitivo de la plataforma, aunque prescindiendo de la colaboración de los usuarios, sin renunciar a todo el contenido ya reunido por la comunidad en Google Earth (Jiménez Cano, 2015).

Los factores que contribuyeron al éxito de Panoramio, además de tener tecnología propia y única, y ser un producto con una visión muy clara, fueron la creación y consolidación de una comunidad, ${ }^{7}$ la calidad de las fotos, y la posibilidad de visualizar diversas imágenes a medida que el usuario se desplaza sobre el mapa de Google Earth (AlicanTEC, s. f.). El usuario de Panoramio es aficionado a la fotografía, o incluso fotógrafo

Figura 2. Las fotos de Panoramio expuestas en Google Earth

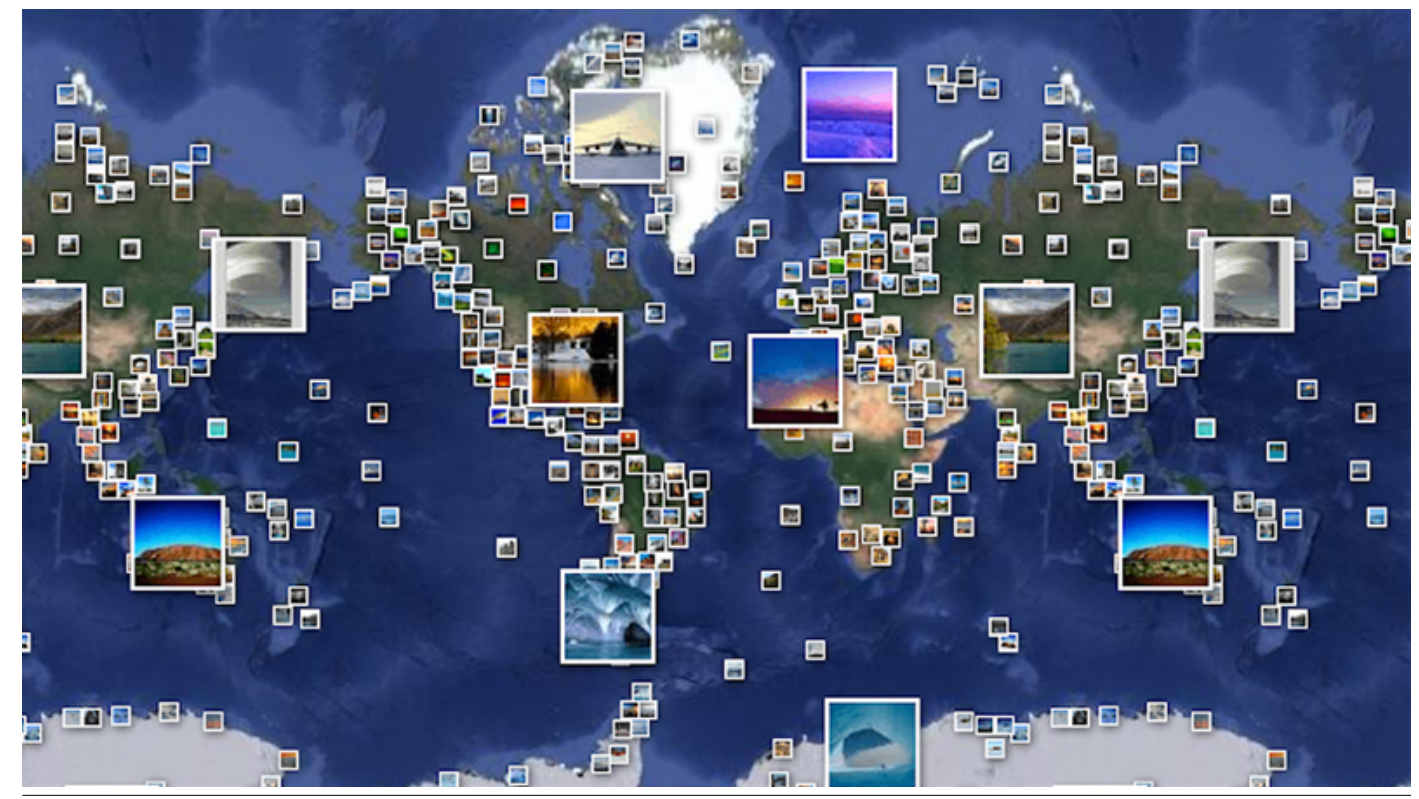

Fuente: artículo Google are gearing up to close image-sharing site Panoramio (Reid, 2016). 
profesional, vinculado a redes sociales; o viajero permanente, interesado en exponer sus tomas y recibir valoración por parte de los demás miembros del grupo. Este actor forma parte de una comunidad consolidada, por lo que es proveedor de información y en muchos casos también evaluador; el espectador o público que consume las fotos es difícil de acotar, porque puede inscribirse a Panoramio, pero no subir una sola foto $y$, sin embargo, incidir en decisiones relacionadas con la exposición pública (o no) de las imágenes compartidas.

La comunidad resultaba clave, además de subir las imágenes de los lugares que visitaban (figura 3 ), de manera voluntaria tradujeron el servicio a más de 40 idiomas y advertían cuando una imagen estaba mal ubicada, era de mala calidad o violaba el código de conducta, ayudando a descartar fotos con contenido inapropiado, mal ubicadas o que mostraran gente o mascotas en primer plano, características que justificaron la selección de la fuente para el ejercicio propuesto. Esta dinámica justifica la pertinencia de la fuente para el ejercicio propuesto, pues las imágenes descargadas - la mayoría de muy buena calidad- se enfocan realmente en capturar escenarios del centro de la ciudad.

\section{La base de datos}

La base de datos con la que se cuenta, descargada desde Panoramio, tiene un poco más de seis mil registros vinculados a las fotos tomadas y compartidas por 1079 usuarios (figura 4), para un área cuyas coordenadas abarcan un ámbito

Figura 3. Intensidad de fotos subidas a Panoramio por usuarios en 2016

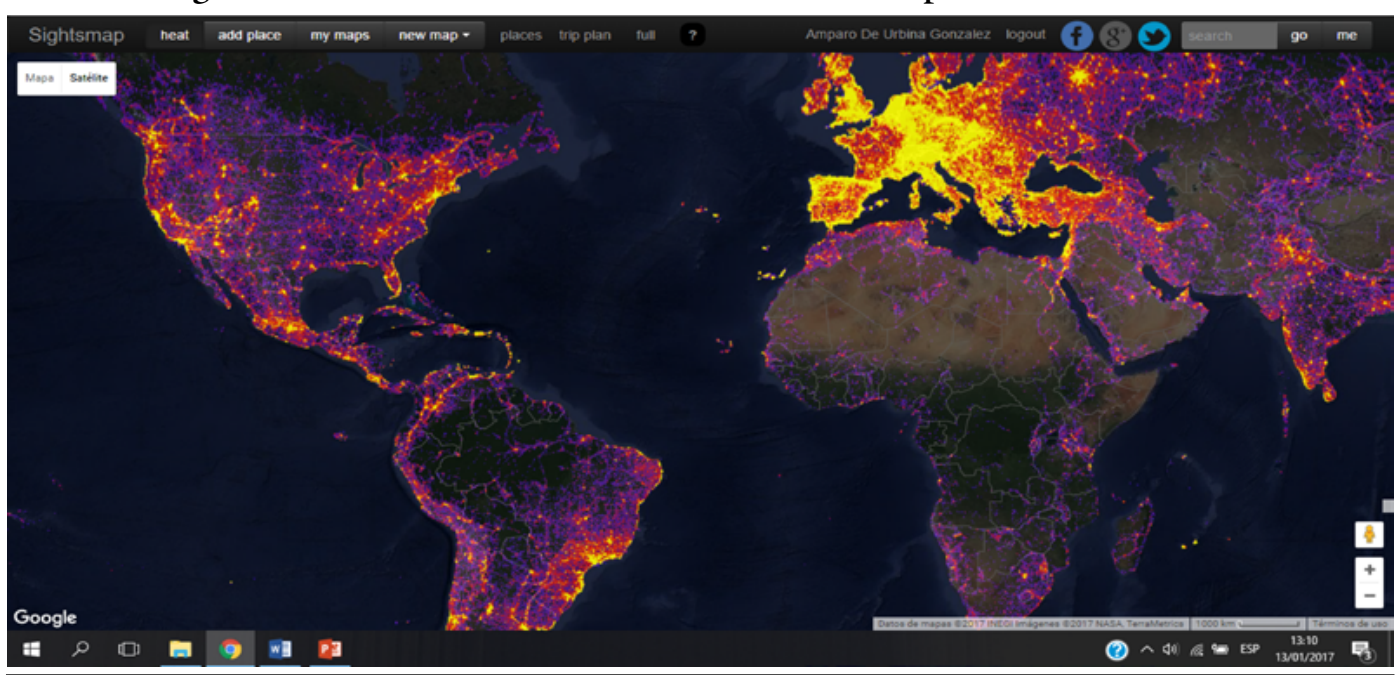

Fuente: página Sightsmap (http://www.sightsmap.com/). 
Figura 4. Ensamblaje de la base de datos

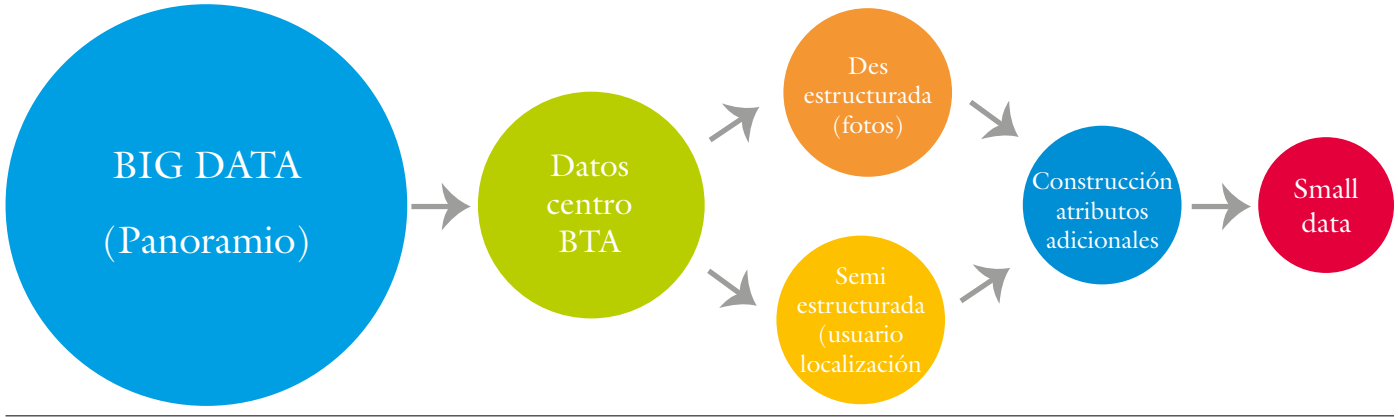

Fuente: elaboración propia.

mayor a los límites político administrativos, vinculados con el centro histórico y su centro ampliado (figura 5). Para descargar las imágenes del área de estudio, así como la información de la plataforma vinculada a cada una (como coordenadas, dimensiones de la foto, usuario que la tomo, fecha, la URL desde donde se descarga la imagen, título, entre otros datos), se recurrió a la API de Panoramio, una biblioteca JavaScript que provee elementos solicitados (Panoramio, s. f.).

Figura 5. Área de descarga de información Panoramio

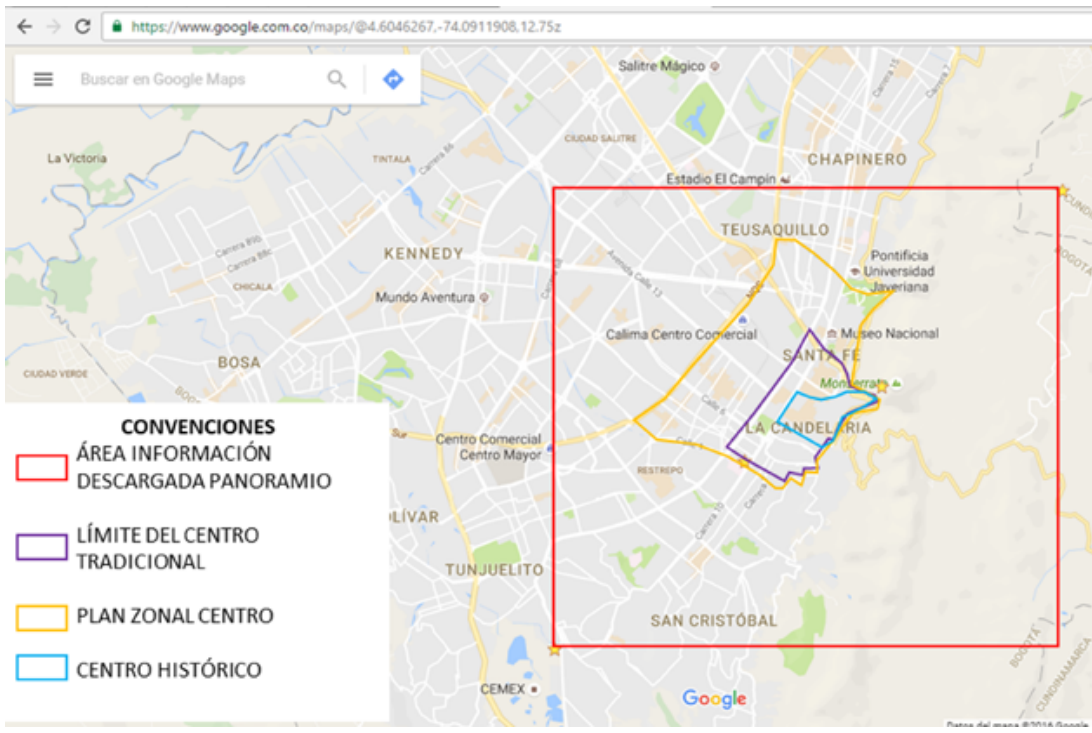


La información en bruto descargada de la API provee dos tipos de datos: desestructurados y semiestructurados. Los datos semiestructurados corresponden a información vinculada con el fotógrafo (número y nombre), temporal (fecha completa de toma de la foto y fecha de subida de la foto), espacial (coordenadas geográficas) (ver figura 6) y de eventos y percepción registrada en los títulos de las fotos. La información desestructurada se refiere a las imágenes, a partir de las cuales se hace un análisis denotativo. La denotación es la cercanía con la realidad, una especie de "objetividad" y fidelidad de la imagen con respecto a lo que se muestra en el encuadre; es la información "tal cual" aparece o la "realidad objetiva" (atributos que dan cuenta del momento del día, día noche, interior o exterior, tendencia de toma de ciertos lugares, etc.).

A partir de la base descargada se construyeron nuevas categorías de análisis definidas por necesidades específicas de la investigación, relacionadas con la imagen o foto (información técnica e información que se construye relacionada con el encuadre), el usuario, el encuadre y los títulos que algunos usuarios dan a algunas fotos. La información relacionada con la foto puede agruparse de la siguiente manera: información técnica de la foto, que se refiere a datos inherentes al archivo; información espacial, se refiere a los atributos de ubicación desde donde se tomó la foto, que se puede relacionar también con las distintas delimitaciones político
Figura 6. Distribución general de las imágenes en el área de estudio

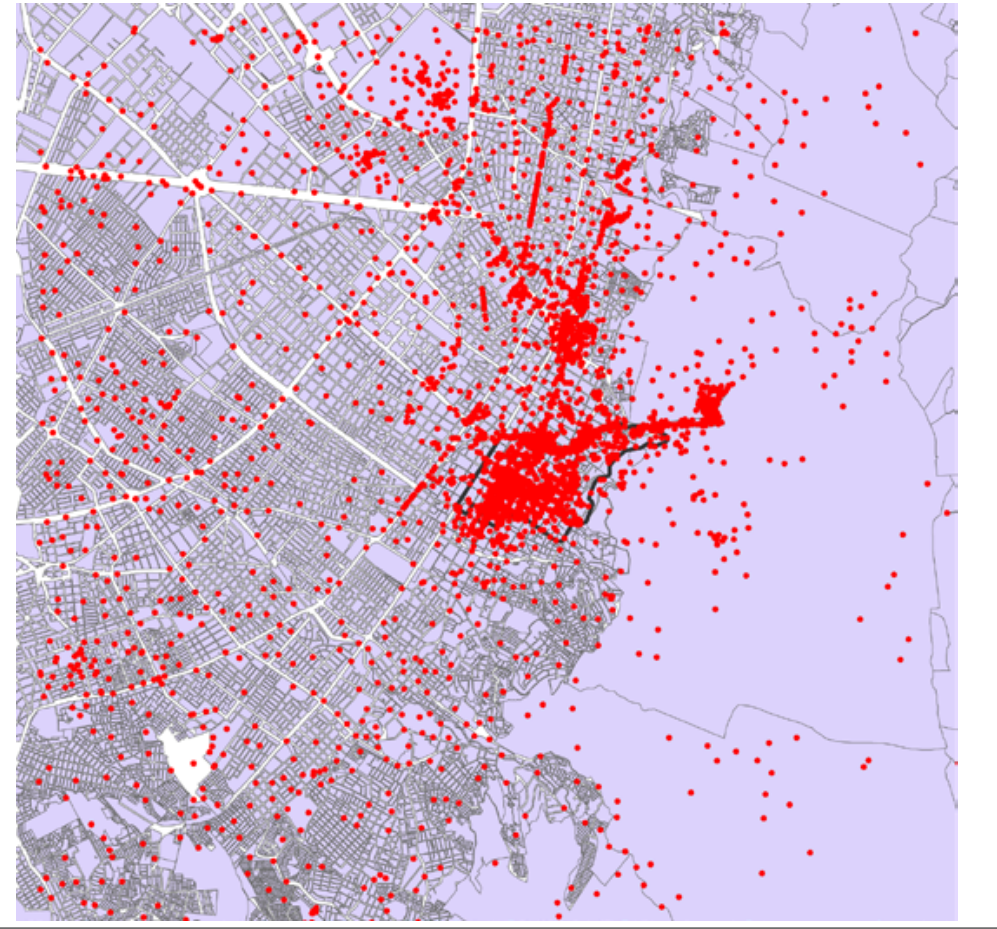

Fuente: elaboración propia.

administrativas del área de estudio, vínculo con manzana catastral o con vías específicas cercanas; información temporal, se refiere especialmente a la fecha de toma de la foto (día, mes, año) y fecha en la que se sube la foto a la plataforma; finalmente, información reconstruida a partir del encuadre, como escenarios más registrados, momento del día (día-noche), interior, exterior, visuales, es decir, los elementos en el territorio más fotografiados, con la intención de identificar hitos del lugar y lugares más frecuentes para capturar panorámicas de la ciudad. territarios 45

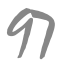


La información del usuario se refiere al nombre, identificador, y cuando fue posible explorando en la red, datos relacionados al origen (local o foráneo) y género; en este ejercicio fue posible identificar que, de los 1079 usuarios de Panoramio en la base de datos construida, la mayoría corresponde a población local que se dedica a registrar y mostrar el centro ( 574 usuarios, de los cuales 405 son hombres y 50 mujeres) y 323 se clasificaron como foráneos (de los cuales 206 son hombres y 34 mujeres). Pero fue posible establecer otros perfiles de actores, más cercanos a agrupaciones, que por supuesto no tienen un género: 17 empresas, tres grupos locales y tres grupos familiares, que podrían entrar en la categoría de familiaridad. Adicionalmente, fue posible establecer que la mayoría de los fotógrafos son hombres (698) y solo 84 son mujeres.

Se extrajo también una buena cantidad de información de los títulos que algunos usuarios le asignan a algunas fotos, con lo que se lograron identificar eventos esporádicos (como protestas), eventos y actividades bianuales, anuales, mensuales, semanales y diarias más relevantes que se dan en el sector; esta información permite ir más allá de la simple descripción física de los escenarios, para relacionarlos con eventos muy puntuales que les dan importancia.

Cuando se acude a fuentes asociadas al Big Data y a redes sociales es inevitable tener un sesgo en la información que es pertinente mencionar. Es decir, es evidente que hay visitantes que no toman fotos, o que no las suben a la red o a esta red específica; por otro lado, es pertinente tener en cuenta que hay lugares de la ciudad - especialmente del centro- donde es prohibido tomar fotos (García et al., 2016). Es por eso que la entrada teórica en la que se enmarca la investigación - Teoría Acto-Red- es tan importante, pues reconoce toda la complejidad de estos análisis y propone, por lo tanto, establecer el ensamblaje específico con el que se va a trabajar; esto permite contextualizar los resultados obtenidos.

El ensamblaje identificado en este caso - como se mencionó en la introducción-considera las relaciones entre el territorio de estudio - legitimado como patrimonio a través de los discursos institucionales-, el visitante, las imágenes que registra con su cámara y Panoramio, con la información recolectada en el área de estudio entre 2007 y 2014. Las relaciones entre todos estos elementos heterogéneos - considerados desde la TAR como actores-, condicionan el abordaje propuesto del centro de Bogotá.

\section{Primeros hallazgos}

\section{Dimensión estética. Las tipologías de encuadre}

Según Barthes, el campo cultural de producción de las fotos se aborda teniendo en cuenta tres categorías: Operator o el fotógrafo, Spectator o los que consumen las 
fotos y Spectrum o lo que es fotografiado. Este último elemento se puede desglosar en los elementos constitutivos de la foto, teniendo en cuenta: el asunto o tema elegido como la arquitectura, la gente, los niños, etc.; la tecnología, es decir los materiales y aspectos tecnológicos que le permiten al fotógrafo hacer su trabajo; las coordenadas de situación, serán el espacio geográfico donde ocurre la fotografía; y, finalmente, el tiempo cronológico, es decir la fecha, época, momento del día en el que se realiza (Suárez, 2008, p. 39). Un ejercicio denotativo del spectrum de las imágenes de la base de datos descargada de Panoramio empezó a revelar ciertas tendencias de encuadre con las que se pueden identificar algunas tipologías de interés de captura del centro de la ciudad en imágenes, esto teniendo en cuenta que una imagen puede tener múltiples lecturas (Banks, 2010).

De las 6035 fotos a las que se les pudo establecer alguna descripción a partir del encuadre, el $90 \%$ son capturadas en exteriores y solo el $8 \%$ en espacios interiores (de esas el $49 \%$ en museos y el $29 \%$ en iglesias); respecto a las fotos tomadas en exteriores, el 93\% fueron capturadas de día, muy pocas, es decir, el $5 \%$ fueron capturadas de noche (la mayor parte de las mismas suelen estar vinculadas con la iluminación navideña) y el $2 \%$ restante en el atardecer. Respecto a las fotos tomadas de día, el 65\% evidenciaron una Bogotá nublada (o lluviosa), mientras que el $30 \%$ una Bogotá soleada; el $5 \%$ de las fotos capturadas en climas de sol y lluvia, tienen el arcoíris como protagonista (figura 7).

Figura 7. Tendencias de encuadre

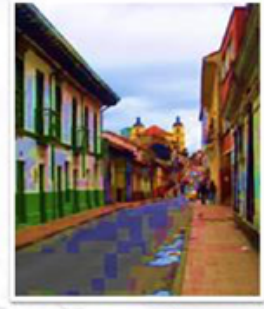

Perspectiva peatonal

Tomadas desde una perspectiva peatonal (3333)

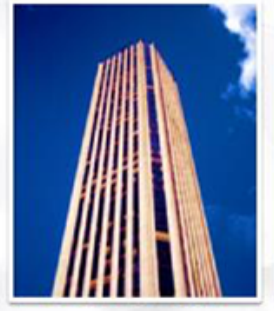

Hacia arriba

(1409) como intentando capturar

los cerros o la Torre Colpatria hasta su ultimo piso

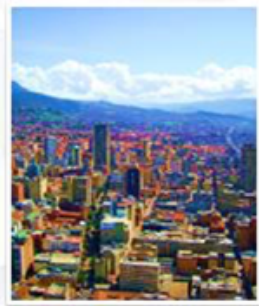

Panorámicas

(579) resultan bastante frecuentes desde los cerros.

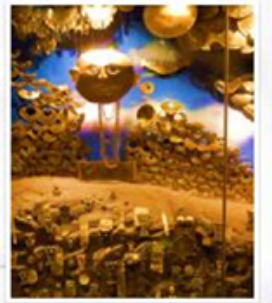

Interior/exterior

5426 fotos fueron tomadas en exteriores, y solo 460 en interiores, la mayoria de las cuales son en museos

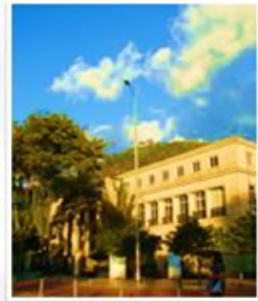

Día/Noche

5515 fotos tomadas en exteriores son de dia, el centro parece poco registrado de noche (281).

Fuente: elaboración propia. 
Las seis tipologías de encuadre más recurrente (Figura 8) son las panorámicas

Figura 8. Tipología general encuadre fotos

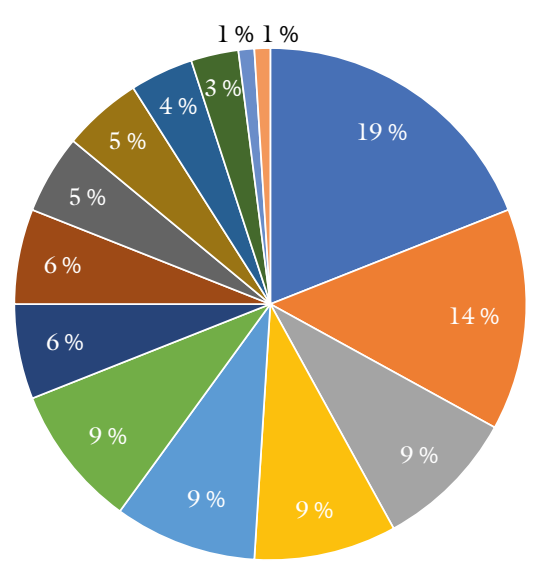

- Panorámicas

- Perfil urbano

- Fach. perspectiva

- Pers. vías estrechas

- Arte urbano material gráfico

- Puertas y ventanas

- Patios

- Escenas

- Pers. vías amplias

- Placas en EP

- Transmilenio

- Casas esquina

- Comida

waroles

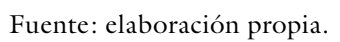

Fuente: elaboración propia.

territarias 45

Fuente: elaboración propia.

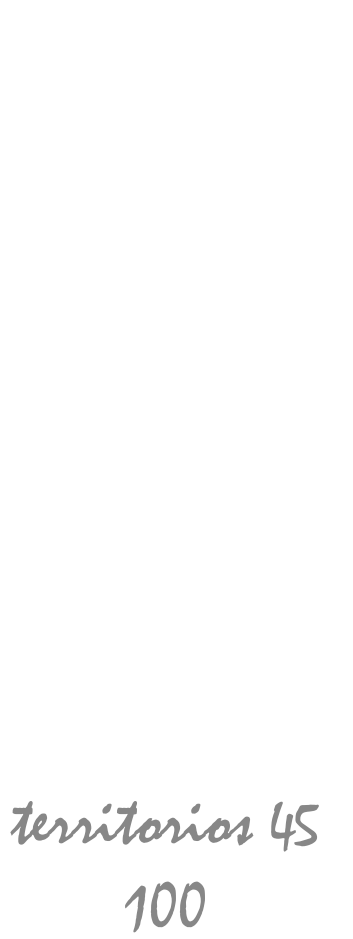

con un $19 \%$, los perfiles urbanos con un $14 \%$, las fachadas, las perspectivas en vías estrechas y el arte urbano y material gráfico y, finalmente, puertas y ventanas cada una con un $9 \%$. Las panorámicas se refieren a imágenes que muestran un panorama a partir de un amplio horizonte y visual, la mayoría de ellas capturadas desde dos lugares muy importantes del centro de Bogotá y al mismo tiempo muy registrados en los encuadres de muchos usuarios: los Cerros y la Torre Colpatria; los principales miradores identificados en los cerros son Monserrate, la Estación Monserrate (incluyendo el recorrido de ascenso y descenso) Guadalupe, Mirador de Choachí y diversos puntos de la Avenida Circunvalar (figura 9).

Figura 9. Principales miradores identificados

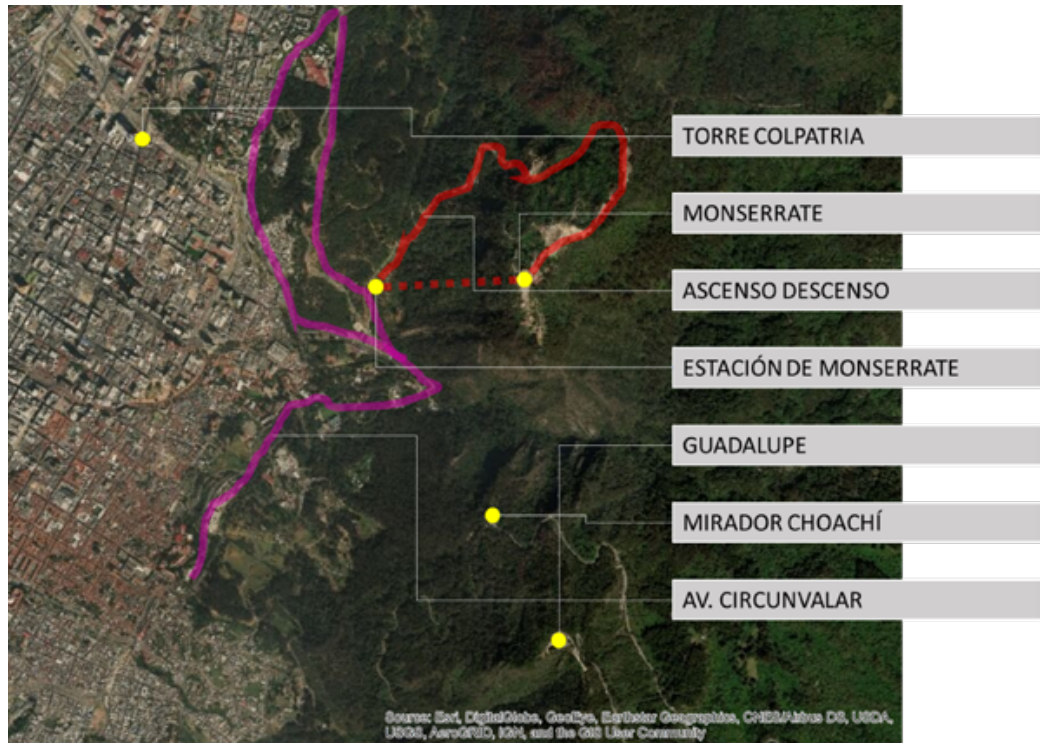


El perfil urbano se refiere a imágenes cuyo encuadre permite dos o más construcciones en una cuadra; el punto de fuga está fuera del encuadre o a punto de salir del mismo, son imágenes capturadas en el centro histórico y centro internacional. La diferencia con la tipología de fachada es que en el encuadre solo figura una construcción. Las perspectivas en vías estrechas son imágenes típicamente capturadas en las calles estrechas del centro histórico, donde el punto de fuga queda dentro del encuadre, buscan la simetría. El arte urbano se refiere a diferentes expresiones de arte, identificadas en centro histórico, y en culatas de construcciones ubicadas en vías amplias como la calle 26.
Y, finalmente, están las puertas y ventanas (figura 10).

\section{Dimensión espacial. \\ La ubicación del fotógrafo}

La información de coordenadas que está asociada a las fotos de la base de datos, está vinculada especialmente al lugar donde se ubicó el fotógrafo para capturar la toma, lo que no necesariamente coincide con el escenario capturado en el encuadre. Esta información resulta interesante pues da una idea de los lugares en el centro de Bogotá, frecuentados por los fotógrafos de la base de datos, resulta también pertinente, como punto de arranque para

Figura 10. Ejemplos principales encuadres
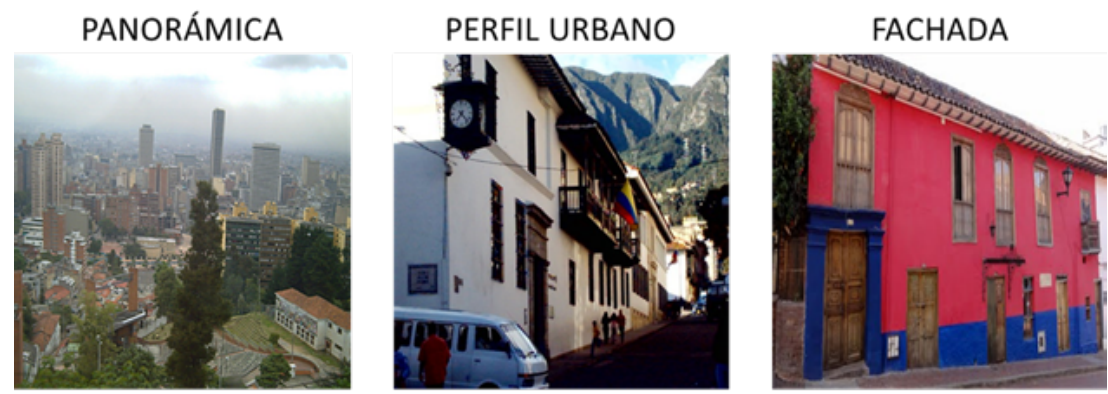

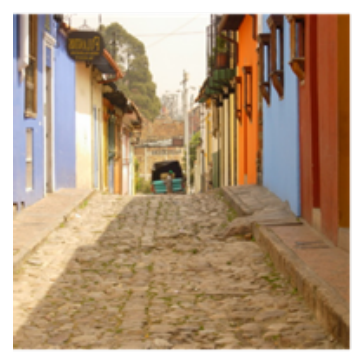

PERSP ESTRECHA

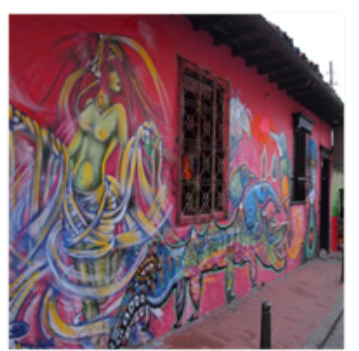

ARTE URBANO

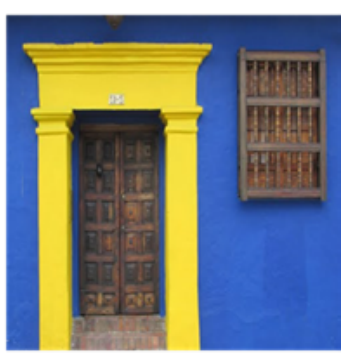

PUERTAS VENTANAS

Fuente: elaboración propia. 
8 Para este ejercicio se acudió a la Densidad de Kernel, un indicador que calcula la densidad de las entidades ajustándose a una superficie curva. identificar los escenarios de interés. Al georreferenciar esta información y hallar la densidad de coordenadas por metro cuadrado, ${ }^{8}$ alrededor de 19 "clusters" parecen evidentes (figuras 11 y 12).

El centro histórico parece un buen lugar para capturar fotos, como muestra la figura 11, con epicentro en la Plaza de Bolívar, Museo Botero, Biblioteca Luis Ángel Arango, Museo del Oro, Plazoleta del Chorro de Quevedo y el eje de la Avenida Jiménez. Hacia el norte del centro histórico están la carrera Séptima con avenida 19, el edificio Colpatria, el Parque de la Independencia, la Plaza de Toros, el Museo Nacional y el Parque
Nacional. Al occidente del centro histórico, todavía dentro de los límites del PEMP, es evidente la concentración de fotos en San Victorino y el Cementerio Central. Más al occidente y fuera de los límites del Plan Zonal Centro están la Universidad Nacional y Corferias, dos grandes sorpresas de la muestra.

Para identificar los lugares más visitados por los fotógrafos de la muestra para capturar imágenes desde la zona no urbana del centro, que en adelante se van a denominar "cerros", se hizo un ejercicio adicional de densidad de fotos, aislando las coordenadas relacionadas con este sector; esto debido a que la cantidad

Figura 11. Densidad de Kernel imágenes por metro cuadrado ( 5 Cortes naturales Jenks)

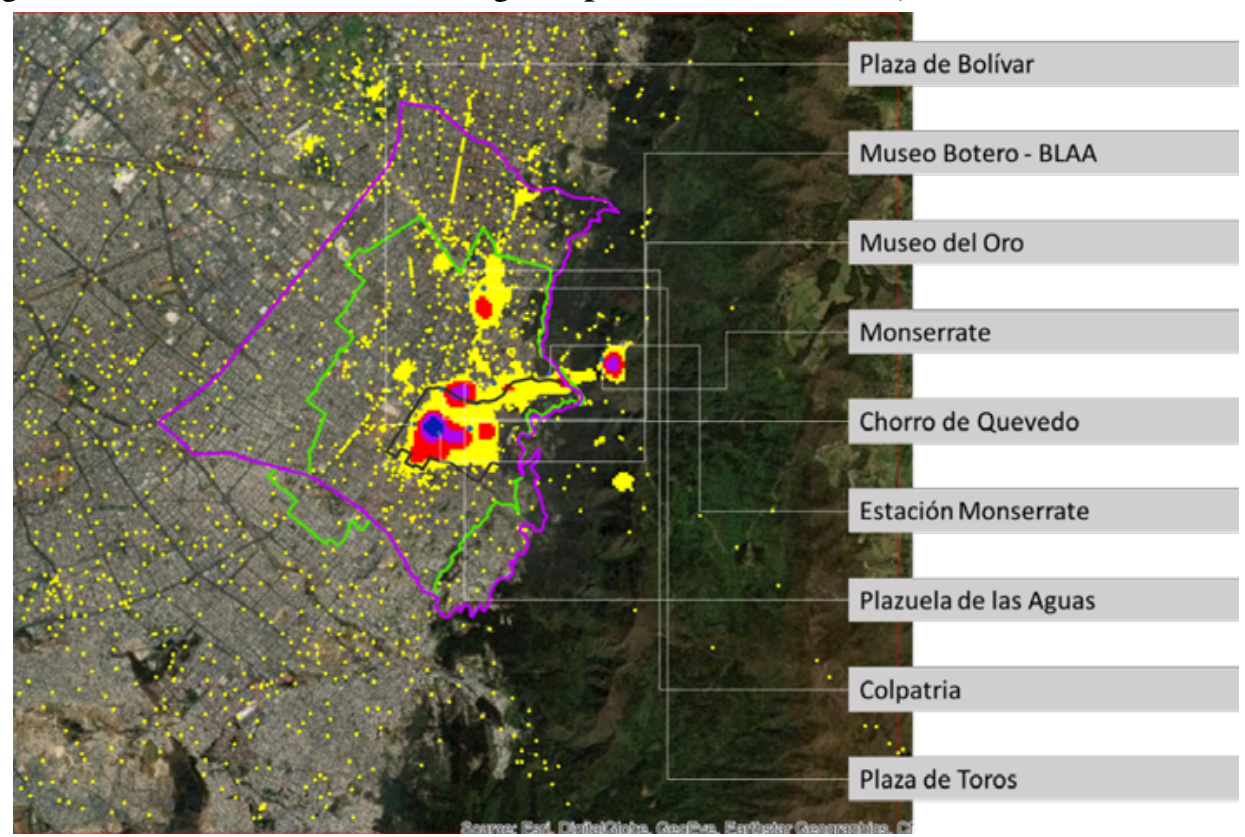

Fuente: elaboración propia. 
Figura 12. Densidad de Kernel imágenes por metro cuadrado (5 Cortes naturales Jenks)

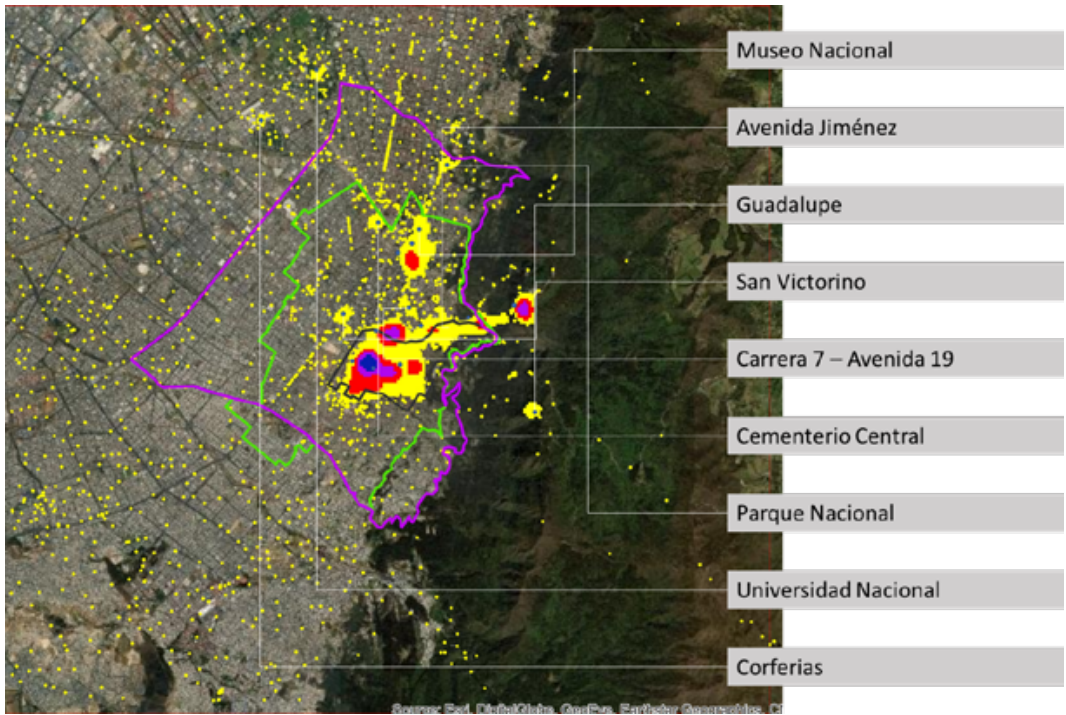

Fuente: elaboración propia.

Figura 13. Densidad de Kernel imágenes por metro cuadrado (10 Cortes naturales Jenks)

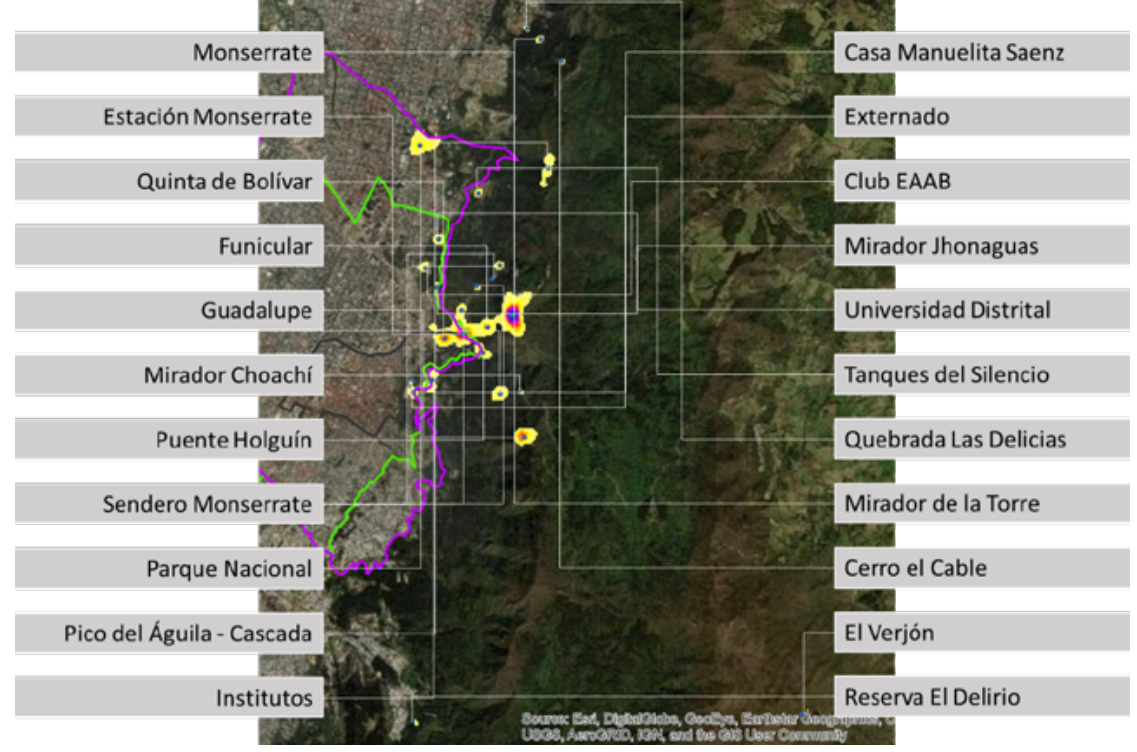

Fuente: elaboración propia. 
de coordenadas relacionadas con la zona urbana (91\%) es tan alta, que se distorsionan los resultados vinculados con los cerros $(9 \%)$, ocultando lugares de interés.

El resultado del ejercicio para los cerros (figura 13) evidencia que sin duda el lugar más visitado por los fotógrafos, o más utilizado para capturar las imágenes compartidas en Panoramio, es lo que se va a denominar el complejo de Monserrate, que incluye todos los lugares de visita relacionados con el cerro de Monserrate, la estación de Monserrate sobre la Avenida Circunvalar, el sendero a Monserrate y el tramo de recorrido que hacen los visitantes desde el funicular y el teleférico. Le siguen en importancia el cerro de Guadalupe, el Mirador de Choachí, la reserva El Delirio, el Pico del Águila y la Cascada, la zona de los Institutos y otros lugares más, con 10 fotos o menos. Otros lugares resultan muy importantes en la información relacionada con los cerros y no tanto con la información urbana, que son la Quinta de Bolívar y el Parque Nacional.

\section{Dimensión temporal. Los eventos}

Si bien, la base de datos muestra la fecha y hora de toma de las fotos (que no necesariamente es igual a la fecha y hora de subida de la foto a la plataforma), al analizar estos datos se encontró que no mostraban mayor relevancia. Solo vale la pena resaltar cuatro momentos importantes de registro del centro, en términos generales, el centro se registra/visita especialmente de día (de la muestra de 5909 fotos disponibles, 5628 fueron capturadas de día y solo 281 de noche), los domingos, en diciembre y en eventos especiales.

Es justamente esa cuarta perspectiva, la de los eventos especiales, la que arrojo resultados muy interesantes. Lo anterior fue posible gracias especialmente a los títulos asignados a algunas de las imágenes de la base de datos, lo que se complementó con la identificación de fotos tomadas justamente en la fecha de cada evento. La lista de eventos identificados, que convocaron o llamaron la atención de los fotógrafos, se clasificó en cuatro categorías: eventuales, anuales, semanales y diarios.

Los eventos "eventuales" se relacionan especialmente con manifestaciones, protestas y exposiciones artísticas en espacio público; marchas por la libertad de secuestrados, manifestaciones estudiantiles, en contra de grupos guerrilleros, se cruzan con exposiciones y muestras colectivas, desarrollándose especialmente en el corredor de la carrera Séptima y rematando en la Plaza de Bolívar. En los eventos anuales es pertinente resaltar la temporada navideña (la mayor parte de fotos nocturnas muestran iluminación navideña), la Semana Santa, las protestas del Día internacional de Trabajo y la celebración del 20 de julio.

Los eventos semanales más importantes se dan los domingos y son el Mercado de las Pulgas, la ciclovía y el septimazo, 
todos sobre el corredor de la carrera Séptima; y, finalmente, dos eventos diarios en dos escenarios opuestos: cambio de Guardia Presidencial en la Plaza de Armas de la Casa de Nariño y el Mercado de las Pulgas de Monserrate, en el cerro de Monserrate.

\section{Para cerrar}

Las imágenes del centro de Bogotá captadas por usuarios de Panoramio y los atributos construidos a partir de los datos de la misma plataforma, permiten hacer una aproximación a este territorio, desde una percepción colectiva, mediatizada por las imágenes obtenidas en el marco del ensamblaje propuesto, provenientes de actores locales y foráneos. La construcción de este insumo de trabajo (con más de seis mil imágenes y 80 atributos para cada una), que permitió la aproximación al territorio de estudio, fue posible gracias al acceso a Panoramio, una fuente Big Data y a todo el trabajo adicional que se desarrolló, como la búsqueda en otras fuentes, verificación de información y construcción de nuevos atributos, para limpiarla y organizarla en un formato estructurado.

La información construida a partir de la base de datos que soporta esta descripción, a grandes rasgos, evidencia tres dimensiones de aproximación al centro de Bogotá: una dimensión estética (los encuadres), una dimensión espacial (la ubicación del fotógrafo) y una temporal (los eventos). Los hallazgos mostrados en esta ponencia presentan un primer acercamiento a cada una de las tres dimensiones del territorio de estudio; el ejercicio debe avanzar hacia una comprensión de estas tres dimensiones, que permita identificar y justificar los escenarios más relevantes, tal como se anuncia en los objetivos.

Por ahora las reflexiones de cierre para este artículo apuntan más a las grandes posibilidades de trabajo que representan las Humanidades Digitales, el acceso a recursos en la web y, por supuesto, a fuentes Big Data y el trabajo más cercano al Small Data; este abordaje representa sin duda más tiempo de trabajo - la construcción de esta base de datos duró casi dos años-, pero un manejo, aprovechamiento y valoración de la fuente mucho más profundo, permite matizar elementos que desde una mirada rápida no podrían evidenciarse. A la investigación que soporta este artículo le faltan muchos análisis de datos, todavía no se ha llegado a la escala micro, a los escenarios urbanos que se propone identificar, pero es algo que se logrará a corto plazo.

\section{Referencias}

AlicanTEC. (s. f.). Caso de éxito: Panoramio. AlicanTEC. https://alicantec. com/caso-exito-panoramio/

Banks, M. (2010). Los datos visuales en investigación cualitativa (Trad. T. Martín \& C. Blanco). Morata. 
Cruz Pérez, L., \& Español Echániz, I. (2009). El paisaje. De la percepción a la gestión. Liteam.

Cullen, G. (1974). Paisaje urbano. Tratado de estética urbanistica. Blume.

Fernández, L. (6 de marzo de 2008). Panoramio o cuando el príncipe encantado se llama Google. El Pais. https://elpais.com/tecnologia/2008/03/06/ actualidad/1204795679_850215. html

García, J. C., Gutiérrez, J., Romanillos, G., \& Salas, H. (29-30 de junio y lde julio de 2016). Patrones espaciales de concentración de turistas en Madrid a partir de datos geolocalizados de redes sociales: Panoramio y Twitter. XVII Congreso Nacional de TIG. Aplicaciones de las Tecnologías de Información Geográfica (TIG) para el desarrollo económico sostenibe. Asociación de Geógrafos de España; Universidad de Málaga, España. http://oa.upm. es/48095/

Gutiérrez-Puebla, J., García-Palomares, J. C., \& Salas-Olmedo, M. H. (2016). Big (Geo) Data en Ciencias Sociales: Retos y Oportunidades. Revista de Estudios Andaluces (REA), 33(1), 1-23. https://doi.org/10.12795/rea.2016. i33.01

Jiménez Cano, R. (18 de junio de 2015). Google indulta a Panoramio. El Pais. https://elpais.com/ tecnologia/2015/06/19/actuali-

\section{tersitarias 45} dad/1434681660_639932.html
Jiménez Cano, R. (22 de septiembre de 2014). Google cierra Panoramio. El Pais. https://elpais.com/ tecnologia/2014/09/22/actualidad/1411363788_779549.html

Lalana, J. L. (2011). El Paisaje Urbano Histórico: modas, paradigmas y olvidos. Revista Ciudades, (14), 15-38. https://doi.org/10.24197/ciudades.14.2011.15-38

Lynch, K. (1998). La imagen de la ciudad. Gustavo Gili.

Meneses Rocha, M. E. (2018). Grandes datos, grandes desafíos para las ciencias sociales. Revista Mexicana de Sociologia, 80(2), 415444. https://.doi.org/10.22201/ iis.01882503p.2018.2.57723

Menezes, C., \& Gândara, J. M. (2015). Los discursos fotográficos de los viajeros. Curitiba - Brasil en Tripadvisor. Estudios y Perspectivas en Turismo, 24(3), 609-627. http://www.redalyc.org/ articulo.oa? $\mathrm{id}=180739769010$

Panoramio. (s. f.). Panoramio API-Muestra las fotos de Panoramio en tu propio sitio web. http://www.panoramio.com/ api/data/api.html

Pardo, S. (2015). Las vistas panorámicas de núcleos urbanos: propuesta para su análisis y aplicación al caso de Andalucía (Tesis doctoral no publicada). Universidad de Málaga, España. http://riuma.uma.es/xmlui/handle/10630/10762

Ponce Solórzano, P. J. (2014). El ensamblaje urbano del turismo en el Centro 
Histórico de Quito: una propuesta de estudios urbanos desde la teoría actor-red (Tesis de maestría). Estudios Urbanos, FLACsO, Quito, Ecuador. http://hdl. handle.net/10469/6837

Portugali, J. (2011). Cognition, Complexity and the City. En J. Portugali, Complexity, Cognition and the city (pp. 113-138). Springer.

Reid, A. (11 de octubre de 2016). Google are gearing up to close imagesharing site Panoramio. First Draft. https://firstdraftnews.org/latest/ geolocation-google-close-panoramioverification-journalism/
Suárez, H. (2008). La fotografía como fuente de sentidos. Flacso. https://flacso. or.cr/publicaciones/150-la-fotografiacomo-fuente-de-sentidos/

Vargas Ulate, G. (2012). Espacio y territorio en el análisis geográfico. Reflexiones, 91(1), 313-326. http://www.redalyc. org/articulo.oa?id=72923937025

Zoido Naranjo, F. (2012). Paisaje urbano. Aportaciones para la definición de un marco teórico, conceptual y metodológico. En C. Delgado Viñas, J. Juaristi Linacero, \& S. Tomé Fernández (Eds.), Ciudades y paisajes urbanos en el siglo XXI (pp. 13-91). Libreria Estvdio. 